\title{
Clinical Significance of Venous Graft Size and Run-Off Segment for Peripheral Bypass Patency
}

Mihail Cheshmedzhiev ${ }^{\star}$, Emil Jordanov, Miroslav Yordanov and Nina Kovacheva

Department of Vascular Surgery, St. Marina University Hospital, Varna, Bulgaria

*Corresponding author: Mihail Cheshmedzhiev, Department of Vascular Surgery, St. Marina University Hospital, Varna, Bulgaria, Tel: 0359888982431; E-mail: mi6046@gmail.com

Rec date: Feb 03, 2015; Acc date: Mar 10, 2015; Pub date: Mar 12, 2015

Copyright: (c) 2015 Cheshmedzhiev M, et al. This is an open-access article distributed under the terms of the Creative Commons Attribution License, which permits unrestricted use, distribution, and reproduction in any medium, provided the original author and source are credited.

\begin{abstract}
Aim: To analyze the one-year-patency of infrainguinal arterial reconstructions in relation to venous graft diameter and length and the run-off segment, when arteries above the proximal anastomosis of the reconstruction are not diseased.

Material and Methods: We compared retrospectively for two-year period the diameter, the length of the used vein and the run-off segment in 107 consecutively constructed infrainguinal autovenous bypasses - 54 patent (not less than 1 year) and 53 failed bypasses Diameter of the vein was measured at the narrowest part of the vein (in all cases this was the area of the distal anastomosis). All bypasses are made with translocated nonreversed vein and the length of the vein was measured after the completion of reconstruction. Volume and pressure of blood flow were measured below the distal anastomosis by the means of ultrasound transit-time flowmetry. For the assessment of run-off segment Fourier analyses of flow and pressure were used and alteration of the amplitudes after intragraft infusion of Prostaglandines was calculated.
\end{abstract}

Results: We compared the alteration in amplitudes in failed and patent for at least 1 year bypasses and estimated that ratio below 2 before and after medicamentous vasodilatation, sets the reconstruction in the group of threatened, as well as graft diameter below $3.5 \mathrm{~mm}$ and length over $40 \mathrm{~cm}$.

Conclusion: Hemodynamic assessment of blood flow below distal anastomosis defines the necessary vein lenght, that is why run-off segment has the most important significance for the patency of the infrainguinal autovenous reconstructions. Shorter grafts with diameter over $3.5 \mathrm{~mm}$ do not guarantee longer patency if distal anastomosis is constructed above diseased run-off segment.

Keywords: Diameter of the venous graft; Length of the venous graft; Venous bypass; Intraoperative flowmetry; Minute volume of flow (MVF); Prostaglandin; Run-off segment.

\section{Introduction}

The high incidence of the peripheral arterial disease (PAD) determines the intensive development of the reconstructive surgery of the vessels of the lower extremities. The most commonly observed risk factors include hypertension, hyperlipidemia, diabetes mellitus and smoking. One third of the arterial occlusions occur in the aorto-iliac segment and the rest of them develop below the inguinal ligament. Setting of firm indications for operative treatment and selecting of postoperative regimen, as well as prediction of patency of bypasses would significantly improve, if more diagnostic criteria were used. Significant efforts are made in intraoperative assessment of results of revascularization procedures. Angiography, measurement of averaged flow, wave form [1-3], flow velocity [4,5], resistance [6-10] and impedance $[11,12]$ were used.

Peripheral vascular resistance gained importance for the graft patency during the previous century. Ascer and other task groups $[13,14]$ measure peripheral vascular resistance in accordance of $\mathrm{Ohm}$ law, but because it is linear vascular resistance, the results are not synonymous. Current technologies give opportunity for analysis of the condition of arteries below the site of measurement. Every periodical function for a time unit, i.e. the flow and pressure, could be subjected to developed by Fourier in 19th century harmonic analysis- fast Fourier transformation (FFT). Despite improvement of revascularization techniques, 5 to $10 \%$ of bypasses fail up to 30 days after reconstruction [15]. Walsh [16] discover that technical mistakes cause $25 \%$ of early thromboses. Patency of each reconstruction depends on combination of 3 different factors - surgical, hemodynamic and biological (diabetes, atherosclerosis [17], hypertension [18]). The surgical factors include the surgical technique (continuous or interrupted sewing technique, the graft material - vein, artery or synthetic material), the geometry of the anastomosis (form and size) and, last but not least, the surgeon's skill and experience. The hemodynamic factor includes the anastomotic inflow, the run-off, characteristics of the flow (turbulent flow with stagnation, separation and recirculation) and the degree of stenosis. The hemodynamic success affects the whole extremity and therefore distal sites of observation are used. Quality of the run-off after surgical or endovascular revascularization has main significance for primary and secondary patency and limb salvation [19-22]. The size of the graft and its quality are also major determinants of the long-term success of intrainguinal reconstructions. The exact measurement of the internal venous diameter is difficult due to the different wall thickness and conical narrowing [23]. Wengerter et al. [24] demonstrate a model of 
increasing patency in venous grafts ranging from $3.0 \mathrm{~mm}$ to $4.0 \mathrm{~mm}$, and Idu et al. [25] consider only a venous graft diameter below $3.5 \mathrm{~mm}$ important for the development of stenoses. Recently, much attention is paid to the question of using reversed or non-reversed grafts, but there is no solid evidence for a longer patency in either technique [26]. The predominant opinion is that size and quality of vein are more critical than the condition of artery to which it is anastomosed. This study aims to assess the clinical significance of the graft size and the run-off arterial segment when arteries above the proximal anastomosis of the reconstruction are not diseased.

\section{Material and Methods}

We compared retrospectively for two-year period the diameter, the length of the used vein and the intraoperative flowmetry data for all failed bypass grafts in the order of of their diagnostics in time (32 with thromboses of the graft and 21 with stenoses of the distal anastomosis) with the results for 54 patients with patent bypass grafts in the order the latter were made and that had been patent for at least 12 months. Patients with stenoses, who refused corrective procedures but later were found to have thrombosis were considered as patients with thrombosed bypass grafts. Only patients who attended their control examinations irregularly were excluded. Control examinations were performed regularly on monthly basis and included duplex ultrasonography and measurement of the ankle-brachial index. Patients with unstable haemodynamics, arrhythmia, and impaired diuresis were excluded from the study, due to contraindication for prostaglandin (PG) administration, as well as the patients who attended irregularly the control examinations for objective and subjective reasons and the patients who passed out. Risk factors include smoking (39\% of the patients), diabetes mellitus (41\%), hypertension (38\%), ischaemic heart disease (31\%), cerebro vascular disease (18\%), Chronic Obstruction Pulmonary Disease (3\%) and preliminary vascular reconstructions and amputations (46\%). The diameter of the graft was measured at its narrowest part which in all cases was the area of the distal anastomosis and the length was measured after the completion of the bypass. Bypasses with a length over $40 \mathrm{~cm}$ (LVGs) - 40 of all are considered long, while those with a length less than $40 \mathrm{~cm}$ (SVGs) - 67 of all are considered short. Fiftyone of the reconstructions had a diameter less than $3.5 \mathrm{~mm}$ and $56-$ over $3.5 \mathrm{~mm}$. We estimated Minute Volume of Flow (MVF) below the distal anastomosis using ultrasound transit time flowmetry and the pressure before and after 5 minute local infusion of medicaments with vasodilatative properties (Prostavasine or Ilomedin). Pressure gauging needle was positioned through the graft or through venous branch at not more than $10 \mathrm{~mm}$ from the flow metering probe. We used Fourier analysis of records of data and calculations of amplitude ratios at 20 $\mathrm{Hz}$ frequency and length $20 \mathrm{sec}$. Alteration of ratios of amplitudes after local infusion of PG was calculated by the comparison of values obtained before and after administration of medicament. F0p/H1p is ratio of basic (F0) and first harmonic (H1) amplitudes of Fourier transformation for pressure $(\mathrm{P})$ and $\mathrm{F} 0 \mathrm{q} / \mathrm{H} 1 \mathrm{q}$ for flow $(\mathrm{Q})$ :

$$
\frac{F_{O p} / H_{1 p}}{F_{o q} / H_{1 q}} / \frac{\left(F_{O P} / H_{1} p\right) v}{\left(F_{O q} / H_{1 q}\right) v}=\frac{Y}{(Y) v}
$$

$\mathrm{Y}$ was used for ratio of amplitudes of pressure and flow before intragraft infusion of medicaments and $(\mathrm{Y})_{\mathrm{v}}$ after infusion. That way we calculated how much decreased the ratio of amplitudes after medicament administration [27].
The means and standard deviations were calculated. The KruskalWallis test were used to compare variables before and after druginduced vasodilation in both groups of bypass grafts (patent and and failed); the level of significance was set at $\mathrm{p}=0.0001$.

\section{Result}

In the postoperative period patients were followed by clinical examination, Ankle Brachial Index (ABI) measurement and duplex ultra sound every month up to 1 year after operation. Criteria for high grade stenosis is accepted to be reduction of ABI and difference in velocities in two adjacent segments of inflow arteries, outflow arteries or the graft $(\mathrm{V} 1 / \mathrm{V} 2)$ over 2.5. These criteria were accepted as indication for control angiography. We compared the alteration of ratio of amplitudes in failed and patent for less than 1 year reconstructions and estimated ratio below 2 before and after medicamentous vasodilatation $-\mathrm{Y} /(\mathrm{Y}) \mathrm{v}<1.9$ distributes the bypass in risk group (Figure 1). In failed reconstructions group, ratio of amplitudes of pressure and flow decreases less than 2 times, where $75 \%$ border is at 1.5 fold decrease. In patent grafts group this ratio is over 2 times, where $25 \%$ border is at 2.2 fold decrease - significant difference $-\mathrm{KW}-\mathrm{H}(1.98)=68.2401 ; \mathrm{p}=0.00000$. Decrease of these ratios over 2 times, suggests preserved distal arterial segment and respectively longer patency of bypass. Venous grafts with a length over $40 \mathrm{~cm}$ and a diameter less than $3.5 \mathrm{~mm}(<3.5-L V G s)$ have shorter patency (Figure 2) but the difference between failed and patent bypasses with a diameter over $3.5 \mathrm{~mm}$ and bigger length (>3.5-LVGs) is significant $-28 \%$ more with thrombosis $(43 \%)$ or stenosis $(21 \%)$. Bypasses with a diameter over $3.5 \mathrm{~mm}$ and a smaller length have the highest patency rate.

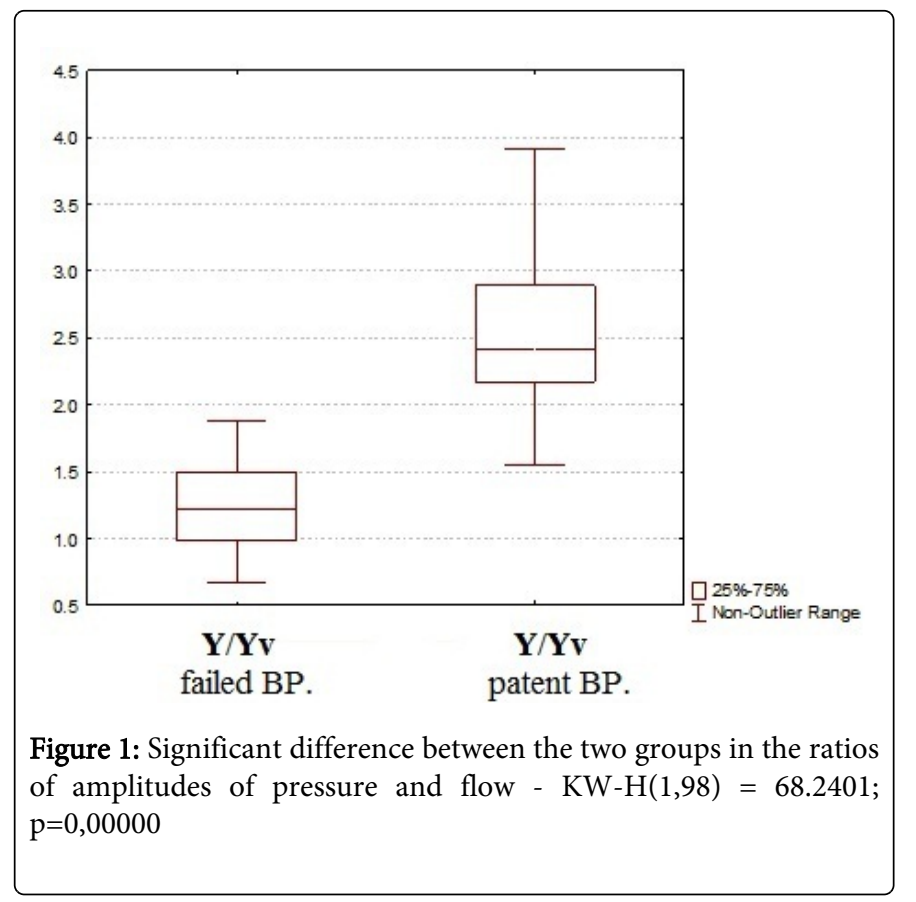

\section{Discussion}

In their study, Tangelder et al. [28] emphasized the significance of 3 main factors for the thrombosis of intrainguinal reconstructions: length of bypass, arterial run-off and the material and diameter of the graft. Smaller length suggests a more preserved venous segment with 
an optimal distal diameter. Meyerson et al. [23] showed that diameter of graft smaller than $3.6 \mathrm{~mm}$ predicts impairment of patency and if established, a different alternative should be chosen.

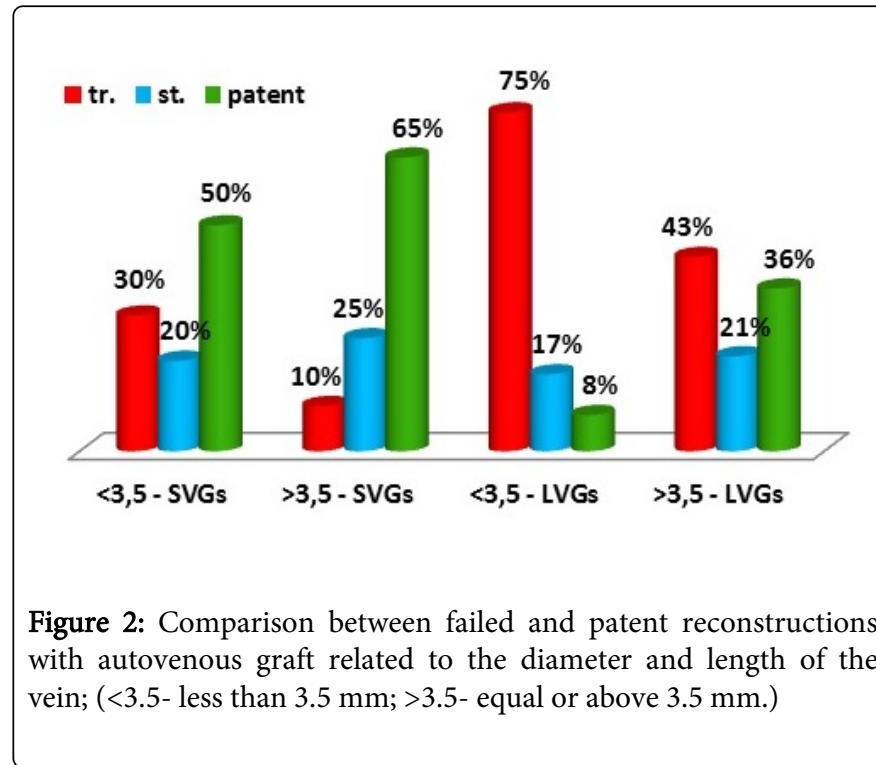

In a multi segmental spread of the disease, especially when the runoff arteries are partially involved, longer grafts are necessary [29], which accounts for the higher rate of the failure of bypasses with a bigger length over patent ones irrespective of their greater diameter (over $3.5 \mathrm{~mm}$ ) by $28 \%$. Grafts with diameter less than $3.5 \mathrm{~mm}$ and smaller length have $50 \%$ probability for patency at least 1 year, if constructed above relatively healthy arterial segment, while a graft with larger diameter and bigger length - 36\%. Some studies have shown that poor run-off affects negatively the patency of infrainguinal reconstructions [30-32]. Patency of infrainguinal bypass and subsequent limb salvation depend crucially on the quality of the distal arterial segment. While assessing the run-off segment, we consider the decrease of intraoperatively obtained results of ratios of amplitudes of pressure and flow after prostaglandin infusion over 1.9-2 times predictive for longer patency of bypass. That conclusion, of course, represents the current state of the distal arterial segment because the spread and the progress of the disease cannot be predicted. We compared retrospectively the diameter, the length of the used vein and the run-off segment in 107 consecutively constructed infrainguinal autovenous bypasses. Only patients who were not regular at their control examinations were excluded. Control examinations were performed monthly and included duplex ultrasonography and measurement of the ankle-brachial index every month up to 1 year after operation. From the study patients with unstable haemodynamics, arrhythmia, and impaired diuresis were excluded,which were contraindicated for prostaglandin (PG) administration. We present a patient who was admitted with thrombosis of left popliteal artery (Figure 3). Thrombectomy of popliteal and anterior tibial artery was performed and subsequent P3posterior tibial artery bypass. The vein had $3 \mathrm{~mm}$ diameters and $12 \mathrm{~cm}$ length. Decrease of ratios of amplitudes of pressure and flow after prostaglandin infusion for posterior tibial artery was 1.5 times and for the front tibial artery 1.4 times. 4 months later a stenosis of the distal anastomosis was diagnosed although the length was smaller. Another case presents patient with thrombosis of superficial femoral artery (Figure 4). Femoro-popliteal (P1) bypass was performed. The vein was
$4 \mathrm{~mm}$ wide and $36 \mathrm{~cm}$ long. Decrease of ratios was 1.5 times. Six months later a stenosis of the distal anastomosis was diagnosed, although length is less than $40 \mathrm{~cm}$ and diameter is larger than $3.5 \mathrm{~mm}$. Autovenous patch of the distal anastomosis was sutured. After eight months thrombosed popliteal artery was diagnosed, but the bypass is patent due to collateral flow which led to P3 segment prolongation. Decrease of the ratios of amplitude of pressure and flow of the rear tibial artery is 1.5 times and for the front artery 1.4. Seven months after that stenoses of the arteries below distal anastomosis was diagnosed.

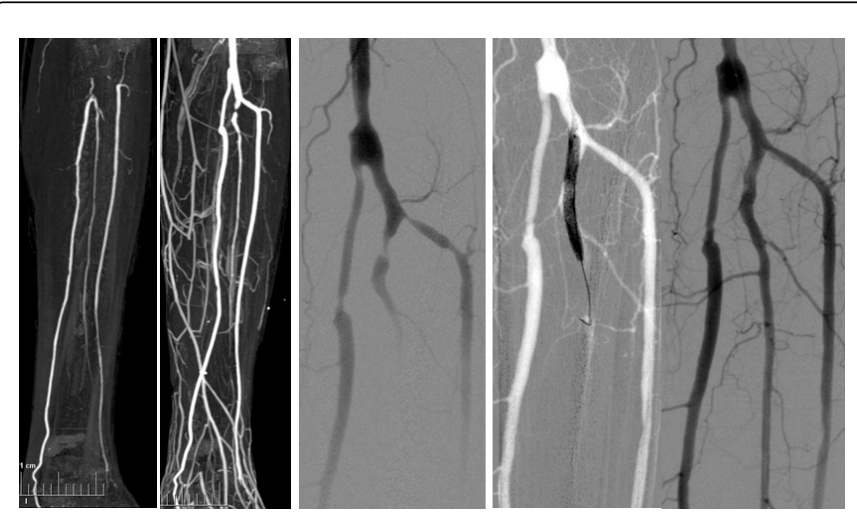

Figure 3: Due to poor data from the flowmetry thorough postoperative follow up was performed. Stenoses of the distal anastomosis were detected, as well as of the peroneal and anterior tibial arteries, which were successfully dilatated 4 months after the reconstruction

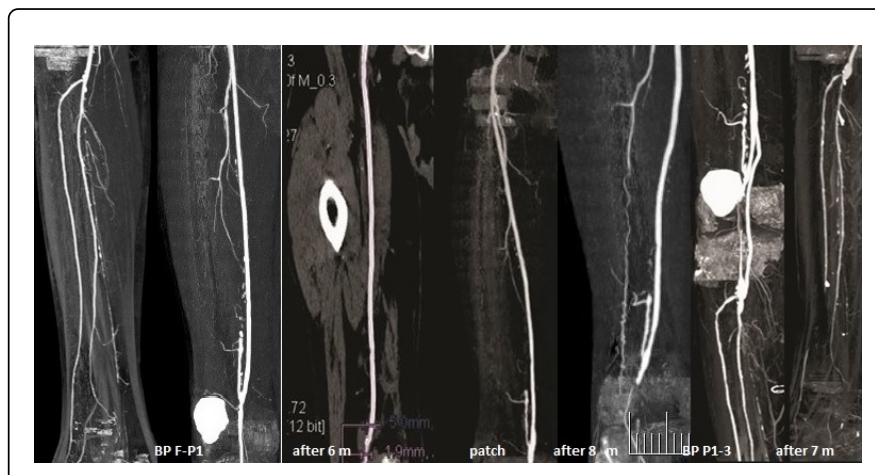

Figure 4: Follow up angiographies of a reconstruction along with patch and bypass placement

Although that angiography of the distal arterial segment looks unsatisfying (Figure 5) in patient with lateral bypass of the tibia (P3 anterior tibial) with diameter of the vein $4 \mathrm{~mm}$ and length $42 \mathrm{~cm}$, decrease of the ratio of amplitudes is 2.2 times. Bypass was followed up patent for 14 months. Comparing values of pressure with those of flow before and after intragraft infusion of prostaglandin, we obtained significant difference between the failed and patent reconstruction groups. Decrease of ratios of amplitudes after infusion of vasodilatative medicament less than 2 times suggests impaired by the disease distal to the reconstruction arterial segment and shorter patency of reconstruction below inguinal ligaments. Best result are derived when a shorter and with larger diameter graft was used. This is achievable with one diseased arterial segment. When a shorter 
segment is impaired more frequently invasive procedures are recommended (i.e. PTA). The larger length of the venous graft is not a critical factor when distal arteries are not diseased, with preserved elasticity, for which testify the data of the intraoperative flowmetry below the distal anastomosis (Figure 5). Crucial to the longer patency is the estimation of the level of the distal anastomosis. The recipient artery should not be diseased. The size and the quality of the graft are also important, as well as the experience of the surgeon. The choice of a vein is very significant. When a good vein on the operated limb is absent, a graft from other limb is chosen, or when not available - a synthetic graft. When the length is not enough a hybrid method is an option - shorter graft and distal angioplasty. Invasive procedures do not improve the quality of the arteries - the effect is limited in time and similar reconstructions require accessory therapy and a closer follow-up (Figure 4). If low flow is observed after infrainguinal reconstructions especially if there is no increase of flow after prostaglandin administration, the reason should be found out and corrected (poor vein, stenosis or improper site of anastomosis, vein twist) to increase the out-flow [33]. Reconstructions that remain with low flow and small alteration of the ratios of amplitudes after medicament vasodilatation have greater risk of failing. These need medicament therapy and intensive postoperative follow-up, if operative correction was not possible. The long term patency of a reconstruction is provided by a good inflow, well processed and positioned graft, sufficient run-off arterial segment, and not least good surgical technique are significant for the longer patency of the infrainguinal reconstructions. We find that intraoperative flowmetry below the distal anastomosis has its value in defining errors immediately after the construction of the bypass, determine the postoperative maintenance therapy and monitoring of the bypass in the risk of thrombosis or stenosis.

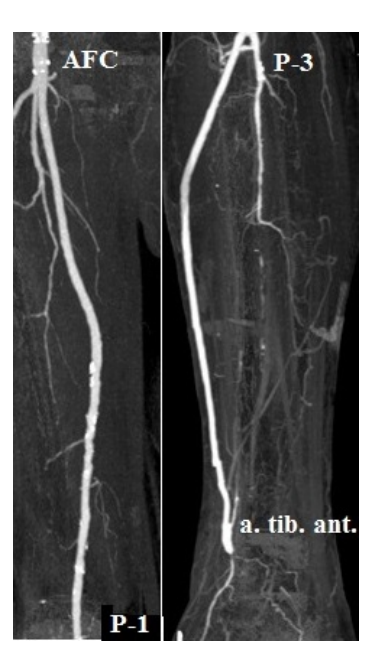

Figure 5: Angiography of the distal arterial

\section{Conclusion}

Shorter grafts with diameter over $3.5 \mathrm{~mm}$ do not guarantee longer patency if distal anastomosis is constructed above diseased run-off segment. Use of short venous grafts is limited in wide spread of the occlusive disease and good quality of longer venous segment is uncertain. Hemodynamic assessment of blood flow below distal anastomosis defines the necessary vein lenght, that is why run-off segment has the most important significance for the patency of the infrainguinal autovenous reconstructions.

\section{References}

1. Andrew A, Pellett S, Edmund K, Kerut (2006) The Doppler ; Velocity Waveform. A Jrnl. of CV Ultrasound \& Applied Tech 23: 528-530.

2. Sensier Y, Bell PR, London NJ (1998) The ability of qualitative assessment of the common femoral Doppler waveform to screen for significant aortoiliac disease. Eur J Vasc Endovasc Surg 15: 357-364.

3. Junger M, Chapman BL, Underwood CJ, Charlesworth D (1984) A comparison between two types of waveform analysis in patients with multisegmental arterial disease. Br J Surg 71: 345-348.

4. Bandyk DF, Mills JL, Gahtan V, Esses GE (1994) Intraoperative duplex scanning of arterial reconstructions: fate of repaired and unrepaired defects. J Vasc Surg 20: 426-432.

5. Belkin M, Mackey WC, McLaughlin R, Umphrey SE, O'Donnell TF (1992) The variation in vein graft flow velocity with luminal diameter and outflow level. J Vasc Surg 15: 991-998.

6. Cheshmedzhiev MV, Knyazhev VV, Radev RS, Yordanov ED (2011) The role of peripheral vascular resistance in determining the infrainguinal arterial reconstruction patency. Folia Med (Plovdiv) 53: 47-52.

7. Ascer E, Veith FJ, White-Flores SA, Morin L, Gupta SK, et al. (1987) Intraoperative outflow resistance as a predictor of late patency of femoropopliteal and infrapopliteal arterial bypasses. J Vasc Surg 5: 820-827.

8. Ascer E, Veith FJ, Morin L, Lesser ML, Gupta SK, et al. (1984) Components of outflow resistance and their correlation with graft patency in lower extremity arterial reconstructions. J Vasc Surg 1: 817-828.

9. Nicholson ML, Beard JD, Horrocks L (1988) Intra-operative inflow resistance measurement: a predictor of steal syndromes following femoro-femoral bypass grafting. Br J Surg 75: 1064-1066.

10. Parvin SD, Evans DH, Bell PR (1985) Peripheral resistance measurement in the assessment of severe peripheral vascular disease. Br J Surg 72: 751-753.

11. Cave FD, Walker A, Naylor GP, Charlesworth D (1976) The hydraulic impedance of the lower limb: its relevance to the success of bypass operations for occlusion of the superficial femoral artery. Br J Surg 63: 408-412.

12. Farrar DJ, Malindzak GS Jr, Johnson G Jr (1977) Large vessel impedance in peripheral atherosclerosis. Circulation 56: II171-178.

13. Ascer E, Veith FJ, Gupta SK, White SA, Bakal CW, et al. (1988) Short vein grafts: a superior option for arterial reconstructions to poor or compromised outflow tracts? J Vasc Surg 7: 370-378.

14. Heise M, Krüger U, Settmacher U, Sklenar S, Neuhaus (1999) A new method of intraoperative hydraulic impedance measurement provides valuable prognostic information about infrainguinal graft patency. J Vasc Surg 30: 301-308.

15. Budd JS, Brennan J, Beard JD, Warren H, Burton PR, et al. (1990) Infrainguinal bypass surgery: factors determining late graft patency. Br J Surg 77: 1382-1387.

16. Walsh DB, Zwolak RM, McDaniel MD, Schneider JR, Cronenwett JL (1990) Intragraft drug infusion as an adjunct to balloon catheter thrombectomy for salvage of thrombosed infragenicular vein grafts: a preliminary report. J Vasc Surg 11: 753-759.

17. van Oostrom MC, van Oostrom O, Quax PH, Verhaar MC, Hoefer IE (2008) Insights into mechanisms behind arteriogenesis: what does the future hold? J Leukoc Biol 84: 1379-1391.

18. Humphrey JD (2008) Mechanisms of arterial remodeling in hypertension: coupled roles of wall shear and intramural stress. Hypertension 52: 195-200.

19. Albäck A, Roth WD, Ihlberg L, Biancari F, Lepäntalo M (2000) Preoperative angiographic score and intraoperative flow as predictors of 
Citation: Cheshmedzhiev M, Jordanov E, Yordanov M, Kovacheva N (2015) Clinical Significance of Venous Graft Size and Run-Off Segment for Peripheral Bypass Patency. J Vasc Med Surg 3: 192. doi:10.4172/2329-6925.1000192

Page 5 of 5

the mid-term patency of infrapopliteal bypass grafts. Eur J Vasc Endovasc Surg 20: 447-453.

20. Seeger JM, Pretus HA, Carlton LC, Flynn TC, Ozaki CK, et al. (1999) Potential predictors of outcome in patients with tissue loss who undergo infrainguinal vein bypass grafting. J Vasc Surg 30: 427-435.

21. Albäck A, Biancari F, Saarinen O, Lepäntalo M (1998) Prediction of the immediate outcome of femoropopliteal saphenous vein bypass by angiographic runoff score. Eur J Vasc Endovasc Surg 15: 220-224.

22. Blankensteijn JD, Gertler JP, Brewster DC, Cambria RP, LaMuraglia GM, et al. (1995) Intraoperative determinants of infrainguinal bypass graft patency: a prospective study. Eur J Vasc Endovasc Surg 9: 375-382.

23. Meyerson SL, Moawad J, Loth F, Skelly CL, Bassiouny HS, et al. (2000) Effective hemodynamic diameter: an intrinsic property of vein grafts with predictive value for patency. J Vasc Surg 31: 910-917.

24. Wengerter KR, Veith FJ, Gupta SK, Ascer E, Rivers SP (1990) Influence of vein size (diameter) on infrapopliteal reversed vein graft patency. J Vasc Surg 11: 525-531.

25. Idu MM, Buth J, Hop WC, Cuypers P, van de Pavoordt ED, et al. (1999) Factors influencing the development of vein-graft stenosis and their significance for clinical management. Eur J Vasc Endovasc Surg 17: 15-21.

26. Gupta AK, Bandyk DF, Cheanvechai D, Johnson BL (1997) Natural history of infrainguinal vein graft stenosis relative to bypass grafting technique. J Vasc Surg 25: 211-220.
27. Cheshmedzhiev M, Mircheva I, Jordanov E, Kovacheva N (2014) Fourier Analysis of Peripheral Blood Pressure and Flow in Intraoperative Assessment of Infrainguinal Arterial Reconstructions Folia Medica 56: 102-108.

28. Tangelder MJ1, Algra A, Lawson JA, Eikelboom BC (2000) Risk factors for occlusion of infrainguinal bypass grafts. Eur J Vasc Endovasc Surg 20: 118-124.

29. Belkin M1, Mackey WC, McLaughlin R, Umphrey SE, O'Donnell TF (1992) The variation in vein graft flow velocity with luminal diameter and outflow level. J Vasc Surg 15: 991-998.

30. Slim H1, Tiwari A, Ahmed A, Ritter JC, Zayed H, et al. (2011) Distal versus ultradistal bypass grafts: amputation-free survival and patency rates in patients with critical leg ischaemia. Eur J Vasc Endovasc Surg 42: 83-88.

31. Donaldson MC1, Mannick JA, Whittemore AD (1992) Causes of primary graft failure after in situ saphenous vein bypass grafting. J Vasc Surg 15: 113-118.

32. Harrington EB1, Harrington ME, Schanzer H, Jacobson JH, Haimov M (1992) The dorsalis pedis bypass--moderate success in difficult situations. J Vasc Surg 15: 409-414.

33. Hobbs SD1, Pinkney T, Sykes TC, Fox AD, Houghton AD (2009) Patency of infra-inguinal vein grafts--effect of intraoperative Doppler assessment and a graft surveillance program. J Vasc Surg 49: 1452-1458. 